\title{
The future of pain pharmacy: driven by need
}

This article was published in the following Dove Press journal:

Integrated Pharmacy Research and Practice

I8 April 2016

Number of times this article has been viewed

\section{Timothy J Atkinson \\ Alev H Gulum \\ William G Forkum}

Veteran Affairs Tennessee Valley Healthcare System, Murfreesboro, TN, USA
Correspondence: Timothy J Atkinson Veteran Affairs Tennessee Valley Healthcare System, 3400 Lebanon Pike, Murfreesboro,TN 37I29, USA

Email timothy.atkinson@va.gov
Background: Opioid prescribing has increased by $\sim 400 \%$ over the past 20 years in the US and has been correlated with dramatic increases in accidental overdose-related deaths. Emerging evidence of serious dose-dependent side effects of opioid analgesics has led to recommendations from multinational pain societies and governments to decrease opioid doses and increase referrals to pain specialists. Demand for pain specialists of all types has increased; however, training programs for health care professionals struggle to satisfy this need.

Objective: The purpose of this article is to highlight the role of clinical pharmacy specialists in pain management and to discuss available residency training programs and subspecialties within each program.

Methods: We surveyed all eleven accredited pharmacy postgraduate year two (PGY-2) Pain and Palliative Care Residency programs in the US. Program information was derived from interviews with residency directors, current residents, program brochures, and residency Web sites. Data collected included core, elective, and longitudinal rotations, with the time frame dedicated to each experience. Primary practice areas, as well as inpatient vs outpatient focus, were also documented. Additionally, a review of the available literature was completed to determine the areas in greatest need for future pain specialists.

Results: Pharmacy pain specialists have been referenced as highly effective additions to interdisciplinary pain management teams. Pharmacists provide expertise in complex pain medication management, which remains the primary focus of most chronic pain encounters. The PGY-2 programs surveyed differ considerably, with the majority providing significant emphasis to either acute pain management or palliative care with brief or limited exposure to chronic pain management. Four of the eleven programs require 2 months of chronic pain management; however, only two of the eleven programs identify chronic pain management as a primary practice setting.

Discussion: Pain specialists in all fields are in high demand; however, the need for health care professionals specialized in chronic pain management probably exceeds that for professionals specialized in acute pain management and palliative care combined. This disparity between disease prevalence and specialty training programs is not reflected in the current residency training structure, nor have additional training programs arisen to fill this critical need.

Conclusion: Health care systems will continue to struggle to meet the demands of patients with chronic pain until significant emphasis is placed on the education and training of health care professionals in this area. Clinical pharmacy should aim to meet this demand through the expansion of PGY-2 training programs and improved didactic education in pharmacy school that reflects the increased need for chronic pain specialists.

Keywords: pain management, clinical pharmacists, pharmacy pain specialists, training programs 


\section{Introduction}

Pain affects more individuals in the US than diabetes, heart disease, and cancer combined. ${ }^{1}$ This high prevalence of both acute and chronic pain in the US is reflected in the $~ 400 \%$ increase in prescription opioid use from 1995 to 2010 as medical boards, pain societies, and the Joint Commission (formerly Joint Commission on Accreditation of Healthcare Organizations) have encouraged providers to focus on the management of chronic pain. Notably, however, the increased opioid prescribing has resulted in a dramatic rise in the number of overdose-related deaths, from 4,030 in 1999 to 16,651 in $2010 .{ }^{2}$ In $2013,22,767$ deaths were attributed to prescription drug overdose and 16,235 (71.3\%) of these deaths involved opioid analgesics. ${ }^{3}$ With the anticipated growth of the aging population and the subsequent increase in the number of patients suffering from pain, it is evident that more effective means of safely prescribing and optimizing these medications are necessary. The increase in opioid prescribing, misuse, and potential dangers of inappropriate use make it apparent that more effective strategies for the management of pain and pain-related medications are required. ${ }^{3}$ Clinical pharmacists have the unique training and knowledge needed to bridge the gap between increased prescribing of high-risk medications and optimization of pain regimens to ensure safer and more effective medication utilization.

Historically, the growth of clinical pharmacy specialists has been driven by high patient and provider demand within a specialty. ${ }^{4-6}$ For example, heightened national awareness of mental health issues increased the demand for trained specialists, leading to the dramatic expansion of pharmacy training programs from 22 programs in 2011 to 50 programs in $2015 .^{7}$ It has been suggested that the time has come for a similar growth in the area of pain management. The purpose of this commentary is to highlight the expanding role of and demand for pharmacy pain specialists, focusing on their unique training, abilities, potential roles in direct patient care, and current state of specialized training programs.

\section{Clinical pharmacy}

Clinical pharmacists have a vital role, as members of a multidisciplinary team, to provide comprehensive disease state management by serving as medication experts providing safe and effective pharmacotherapy. According to the American College of Clinical Pharmacy, clinical pharmacy is:

A discipline where pharmacists provide patient care to optimize medication therapy utilizing specialized therapeutic knowledge, experience, and judgment for the purpose of ensuring optimal patient outcomes. ${ }^{8}$

Upon graduation from an accredited college of pharmacy, pharmacists receive their Doctor of Pharmacy (PharmD) degree and may subsequently choose to pursue advanced training through a residency program or enter immediately into clinical practice. ${ }^{9}$ Although additional residency training is optional, it is routinely considered a requirement to participate in clinical practice and direct patient care. Most postgraduate year one (PGY-1) residencies provide a broad range of experiences to develop pharmacists into well-rounded clinicians. ${ }^{10}$ Postgraduate year two (PGY-2) pharmacy residencies are structured to provide a more specialized training experience within a specialty, such as cardiology, oncology, or ambulatory care. A clinical pharmacy specialist can serve as a provider and, in most practice settings, operate within a collaborative practice agreement with a scope for practice and prescriptive authority.

\section{Advantages of including pharmacists in pain management}

Incorporation of a multidisciplinary approach to pain management has been shown to result in improved clinical outcomes in chronic pain compared with standard medical practice. ${ }^{11-14}$ Many interdisciplinary pain clinics are overseen by physicians who are board certified in physiatry, anesthesiology, or neurology, sometimes with dual credentials in pain management. Their focus is to complete the initial physical assessments and make recommendations for procedural interventions as part of a comprehensive plan of care, while the subsequent follow-up and medication management is generally completed by nurse practitioners and physician assistants. Further, physical therapists play an important role in physical rehabilitation, whereas social workers and psychologists generally focus on behavioral health. ${ }^{11-13}$ Analgesics are generally the main therapeutic choice during physician or emergency room visits. ${ }^{15}$ As such, pharmacotherapy remains an inherently integral component of pain management, and appropriate prescribing, monitoring, and titration of these often high-risk medications continue to be a burden on health care providers. Patient adherence is a concern in many practice settings; however, pain management has unique challenges in this area. Most of these challenges are centered on medication use, with particular attention, or lack thereof, to opioids. Screening and assessment for high-risk behaviors are critical in pain management, and these behaviors may include "doctor shopping", overuse of prescribed 
pain medications, use of unprescribed medication, illicit drug use, and diversion of opioids, which may indicate addiction and/or dependence. Implementation of universal precautions including urine drug testing, querying state prescription drug monitoring programs, and obtaining patients' informed consent are designed to provide routine assessment for high-risk behaviors. Notably, however, these high-risk behaviors are often only elucidated after discussion regarding specifics of medication use. Clinical pharmacists are well trained in monitoring and assessing medication adherence, making them ideal providers to evaluate progress toward treatment goals. Unlike other pain management clinicians, pharmacists' training is focused on the very aspect of pain treatment that remains frustrating to providers and potentially dangerous to patients: the medications.

Recent evidence suggests that pharmacist-led medication review in the setting of chronic pain management reduced overall pain intensity, improved physical functioning, and increased patient satisfaction. ${ }^{16,17}$ A pharmacy pain specialist uses a unique skill set with advanced training in pharmacokinetics, pharmacodynamics, pharmaceutics, pharmacogenetics, pharmacology, and therapeutics, giving them insight into common barriers to the successful use of pharmacotherapy for pain. These specialists are often relied upon to provide unique solutions to complex patient situations, wherein typical drug delivery is not tolerated or appropriate. As pharmacy pain specialists provide guidance regarding alternative drug delivery or tailored titration schedules, treatment outcomes with medications are often improved. Furthermore, patients have identified that a longer consultation time, in-depth specialized knowledge of pain and pain treatments, and pharmacist's ability to take time to listen and understand patient-specific needs and goals were advantages of a pharmacist- and nurse-run pain clinic over management by general practitioners. ${ }^{18}$ Pharmacists are trained to assess reported medication-related side effects and determine if they are serious, transient, or consistent with clinical trial experience in order to provide appropriate guidance to concerned patients. Counseling in this area helps prevent unnecessary discontinuations and ensure adequate trials of medications to properly assess therapeutic effect. Adjunct medications, in particular, are challenging to manage because patients are often intolerant to side effects or become frustrated with lack of efficacy at subtherapeutic doses. Treatment with adjunct medications is further complicated in patients who routinely report unacceptable side effects to all nonopioid medications, which often leads to suspicion of opioid dependence and increased provider frustration.
Selection of suboptimal analgesics, inadequate monitoring, and polypharmacy contribute to the potential for side effects and, ultimately, inadequate management of chronic pain. ${ }^{19,20}$ Whether monitoring for adverse effects, evaluating mechanisms of action to determine most effective treatments, identifying potential drug interactions, or redesigning regimens based on side effect profiles, it is evident that no other health professional is as uniquely tailored to the management of pharmacotherapy as a pharmacist. ${ }^{11}$ Pharmacy pain specialists provide patient education on how medications work, expected therapeutic range, transient side effects, appropriate medications for pain etiology, and realistic expectations with care. Experienced pain specialists understand the value of timely follow-up to address concerns after initiation of new medications and provide reassurance and additional education when needed. Occasionally, pain pharmacists may take on the role of prescriber to assist with management. ${ }^{21}$ As such, clinical pharmacists bring a unique perspective to evaluate the complex medication regimens frequently used in pain management. Benefits of the inclusion of pharmacists in pain management, however, are not limited to the inpatient or clinic setting. A study reviewing community pharmacist participation in the multidisciplinary management of chronic knee osteoarthritis found that pharmacist participation in care improved patient-reported markers for quality of care, pain function, and quality of life compared with standards of practice. ${ }^{22}$

Available evidence suggests that increasing pharmacist presence in interdisciplinary pain management teams may improve outcomes through optimizing medication selection and doses, improving adherence through effective counseling, and reducing potentially preventable drug-related side effects. As the number of individuals with ineffectively treated pain continues to grow and the risks of misuse and abuse rise accordingly, pharmacists with specialty training in pain management can serve as an asset to providers and teams through guiding medication management in various practice settings. ${ }^{11}$

\section{Driven by need}

Over the past few years, state and national guidelines surrounding opioid therapy have repeatedly changed the definition of "high-dose" opioid therapy (200 mg morphine equivalent daily dose [MEDD] $\rightarrow 120 \mathrm{mg}$ MEDD $\rightarrow 91 \mathrm{mg}$ MEDD) to reflect the tremendous amount of emerging evidence highlighting associations between opioid therapy and risk of dose-dependent side effects and overdose. ${ }^{23}$ Nevertheless, these very same guidelines, and some state laws, 
now recommend that patients receiving high-dose opioid therapy be referred to pain specialty practices with the goal of minimizing opioid use, while simultaneously increasing utilization of adjunct medications, interventional procedures, and nonpharmacologic modalities. Unfortunately, legislating or recommending increasing referrals to pain specialists increases demand but does not produce additional trained specialists.

Clinicians throughout the country are now tasked with managing the consequences of the previous era of "no ceiling effect" as patients struggle to deescalate opioid therapy. Patients managed on high-dose opioid therapy for years often feel punished as therapy suddenly changes direction and considerable time is often required to provide education and support. Patients with pain are caught in the middle as primary care providers are often uncomfortable prescribing their opioids and managing their pain given the shift in guidance and perception that pain pharmacotherapy is too complex. Physicians practicing in various settings report that the current level of training received is "not adequate to appropriately manage chronic pain". ${ }^{24-27}$ In a survey of Veterans Affairs primary care providers, 73\% reported that patients with chronic pain are a major source of frustration, and $38 \%$ reported dissatisfaction with their ability to provide optimal pain treatment. ${ }^{28}$ Notwithstanding this, approximately half of patients suffering from chronic pain are currently managed in the primary care setting. ${ }^{27}$ The result is an unprecedented demand for pain specialists of all types.

Pain specialists with advanced training focused on collaborative drug therapy management are rare, yet medications remain the focus of most encounters in pain management. Ideally, providers with specialized training in pain medication management would not only be available but enjoy this challenging aspect of patient care. As pain management continues to dominate the national stage, the authors predict the next major expansion in clinical pharmacy practice will, or at least should, center on training additional pharmacy pain specialists to meet this demand. Although clinical pharmacy specialists in pain management are rare, they will be highly sought after as demand for their services and expertise continues to grow. While providers view pain management as a high priority, lack of pain management resources and support were identified as barriers to effective treatment. ${ }^{27}$

One recommendation by the Institute of Medicine's report "Relieving Pain in America: A Blueprint for Transforming Prevention, Care, Education, and Research" in 2011 was to increase the number of health professionals with advanced expertise in pain care. This guidance focuses on education programs for all health care professionals and stakeholders, including medical, dental, nursing, mental health, physical therapy, and pharmacy specialists, to train providers to offer advanced pain care. ${ }^{1}$ Because education and training of pain specialists of all types have been identified as major barriers to improving patient outcomes, an examination of the current state of pharmacy pain specialty training programs is appropriate. Pharmacy pain specialists are uncommon even among other clinical pharmacy specialists, with few training programs available, creating an incredible disparity between disease prevalence and lack of trained specialists (Figure 1). There are currently only eleven accredited PGY-2 Pharmacy Pain and Palliative Care Residency programs available, training $\sim 13$ specialists per year, and an additional two programs in development, which have recently been granted precandidate status. ${ }^{29}$

To evaluate the current state of specialty training programs in pain management, we surveyed all eleven Pharmacy PGY-2 Pain and Palliative Care Residency programs in the US. We asked program-specific questions regarding core and elective rotation experiences, longitudinal experiences, primary practice settings, and whether the program was more inpatient or outpatient focused. Table 1 includes a summary and comparison of the available residency programs and reflects information provided from survey responses and program materials. Due to limitations with space and in an effort to highlight unique characteristics, some experiences common to nearly every program, including orientation, research, academia, administration, drug information, teaching certificate, and staffing responsibilities, were omitted. In general, these programs attempt to follow the American Society of Health-System Pharmacists (ASHP) guidance on suggested rotation experiences but also note that they adapt elective experiences based upon the interests of their resident(s). ASHP guidance recommendations for core rotations include experiences across three major practice environments for pain, including acute pain, hospice/palliative care, and chronic pain. ${ }^{30}$ Whether these experiences are inpatient or outpatient focused is site specific and often depends heavily on availability and the practice site. It was noted that while the intent is for a balanced training experience to prepare future pain specialists for a broad range of practice environments, most residency programs have significant program emphasis in one area of practice often reflective of the primary practice site of the residency director.

The number of rotational experiences offered at many of these programs is impressive; however, it is apparent after 
A

Chronic disease prevalence

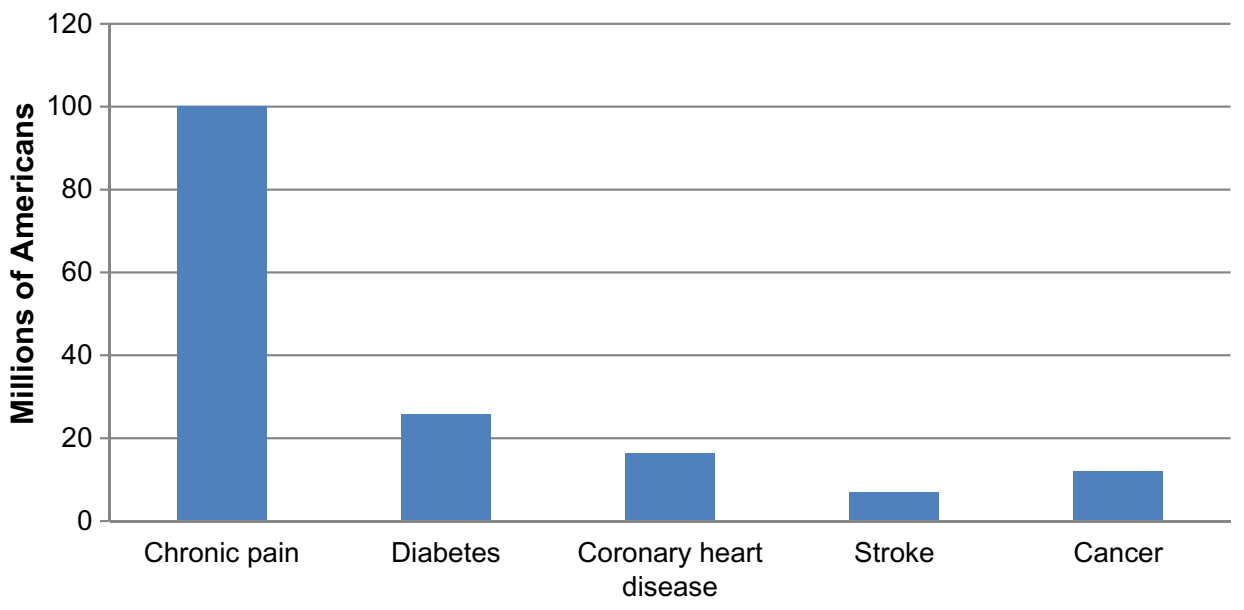

B

Select PGY-2 residency programs

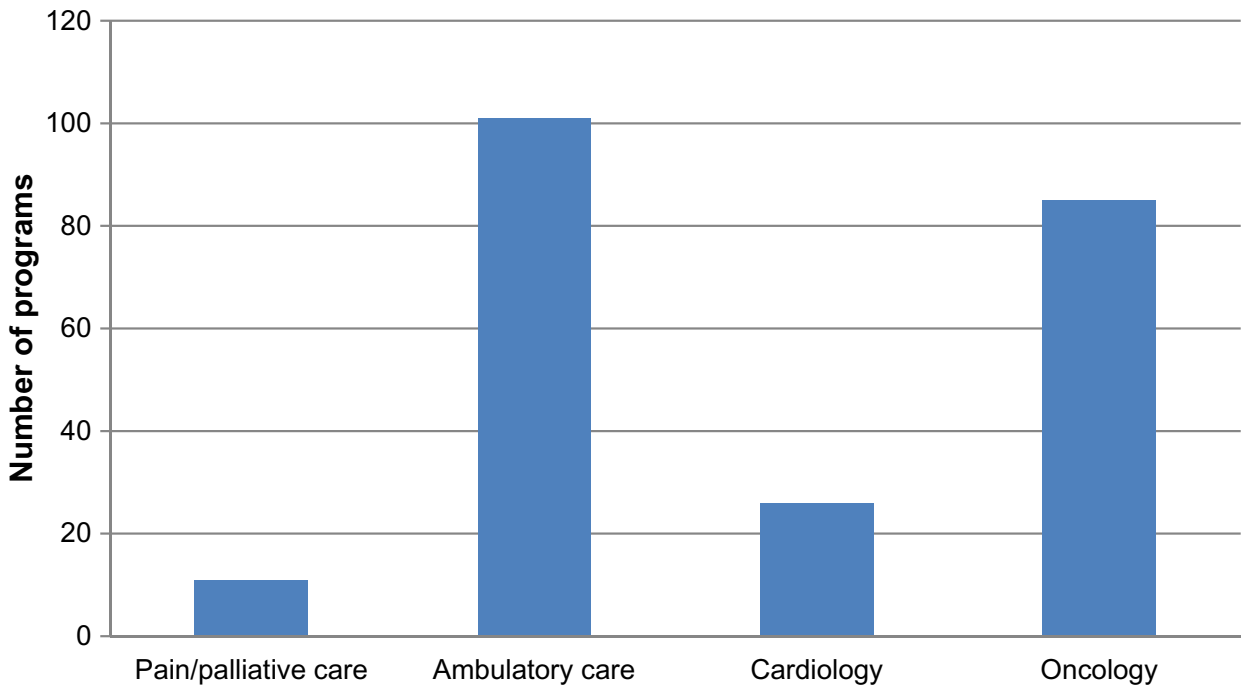

Figure I Comparison of disease prevalence and specialty training programs.

Notes: (A) Data obtained from 2008 reported in 201 I IOM report. Data from American Society of Health-System Pharmacists, ${ }^{29}$ Institute of Medicine, ${ }^{1}$ American Diabetes Association, ${ }^{35}$ Centers for Disease Control and Prevention, ${ }^{36}$ and American Cancer Society ${ }^{37}$ (B) Data from 2015 National Matching Statistics. ${ }^{7}$

Abbreviations: IOM, Institute of Medicine; PGY-2, postgraduate year two.

reviewing each program that most residencies are designed to deliver concentrated experiences in hospice/end-of-life care and acute pain. In addition, although several programs note that inpatient and outpatient training experiences are evenly split, most programs allocate considerable time to practice in the inpatient setting. Of note, seven of the programs reviewed require some form of outpatient chronic pain management as a core rotation and four programs require a minimum of 2 months in this setting. But, of the eleven accredited residency programs reviewed, only two identify chronic pain management as the primary practice setting. It may not be practical or feasible at some sites to deliver extensive outpatient chronic pain management experiences, and it was found that some sites offer the majority of these outpatient chronic pain experiences as electives or longitudinal learning experiences.

There are fundamental differences between pain subspecialties, rendering it difficult to achieve balance in any of these residency programs. For example, hospice/palliative care is focused on symptom management, as well as end-of-life and family counseling, with useful experiences in hematology/ oncology, hospice (inpatient/outpatient), and internal medicine. Furthermore, acute pain management is focused on surgery, perioperative pain management, and severe pain exacerbations, with useful experiences in acute pain service, critical care, and inpatient palliative care. There is significant overlap and relevance in cross-training between acute pain management and palliative care; however, there is distinctly less crossover 


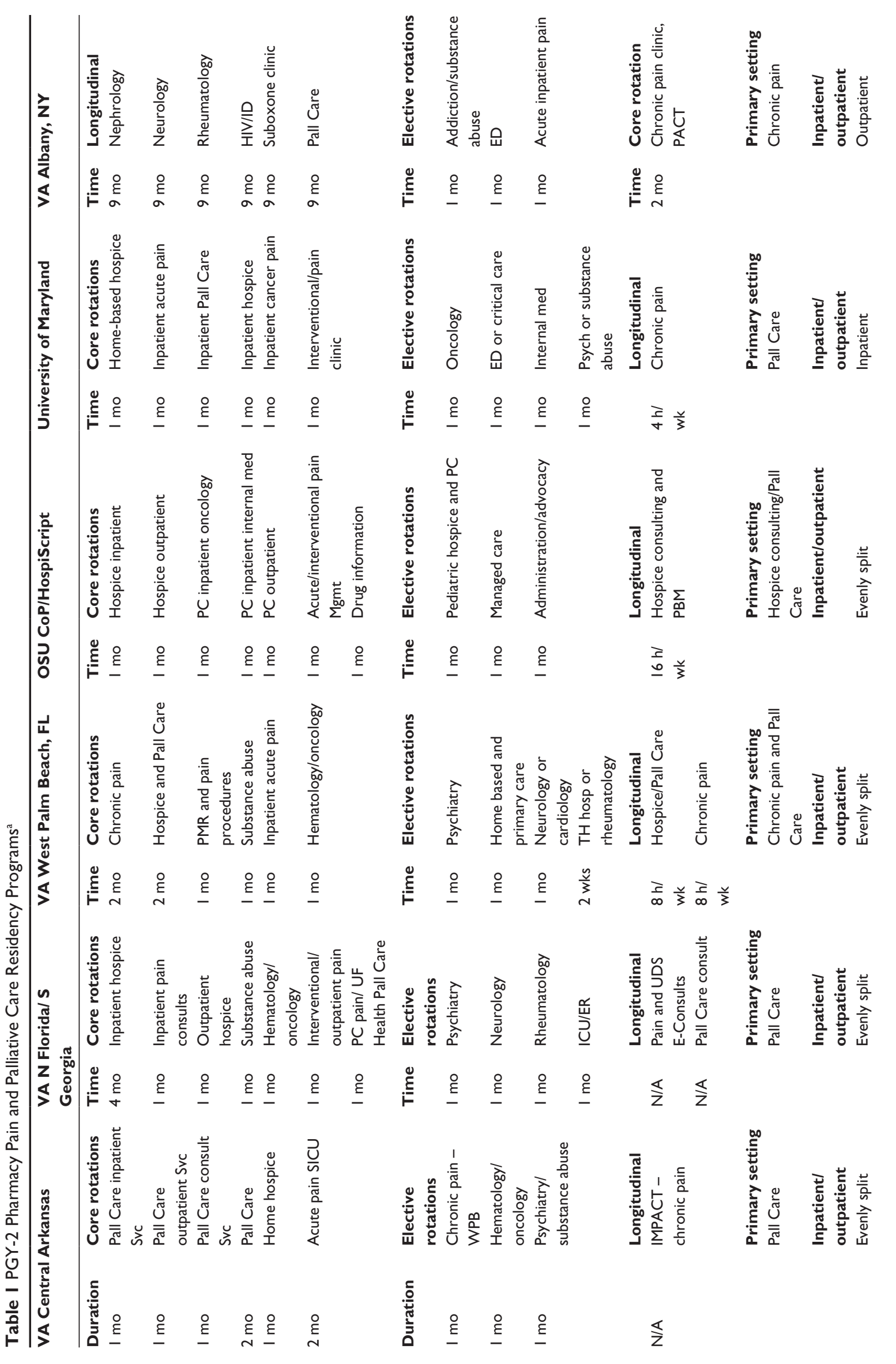




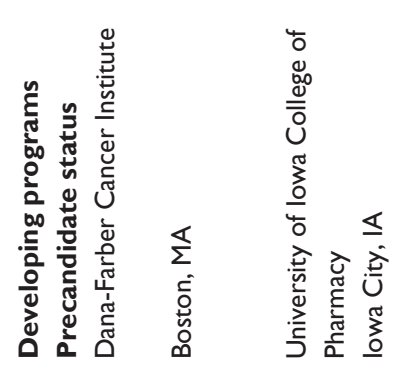

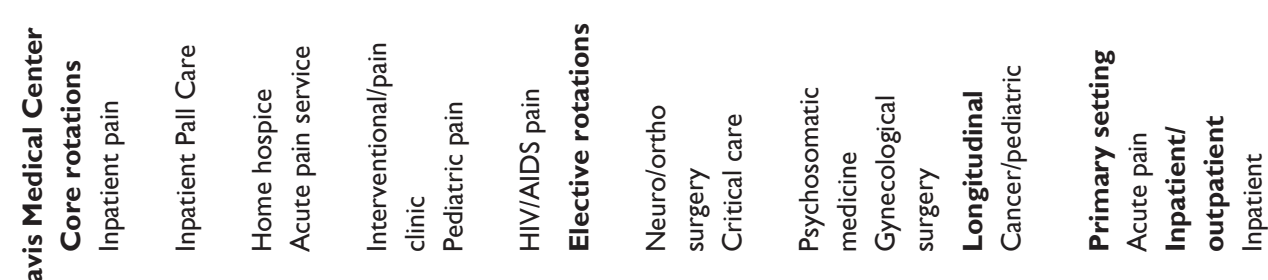

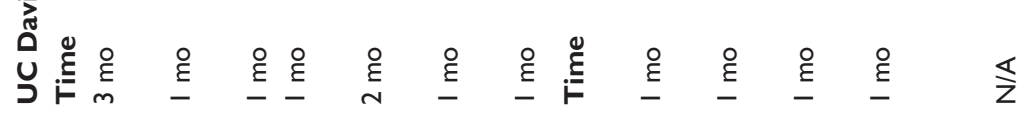

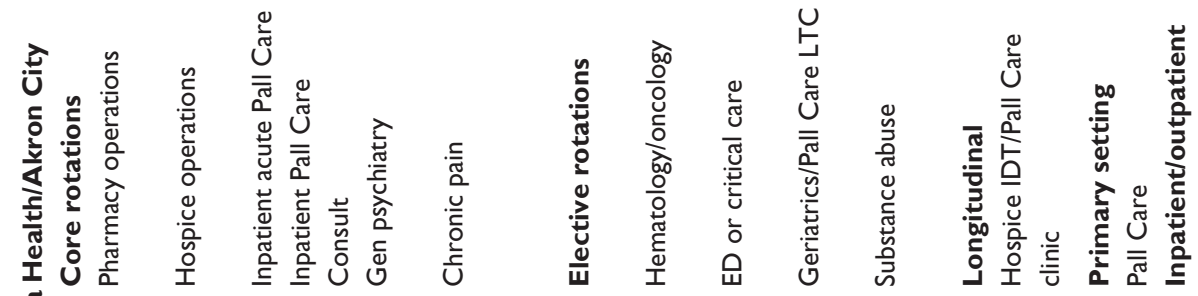

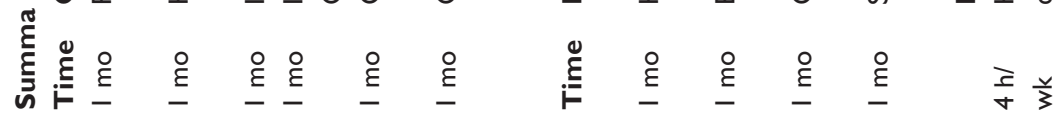

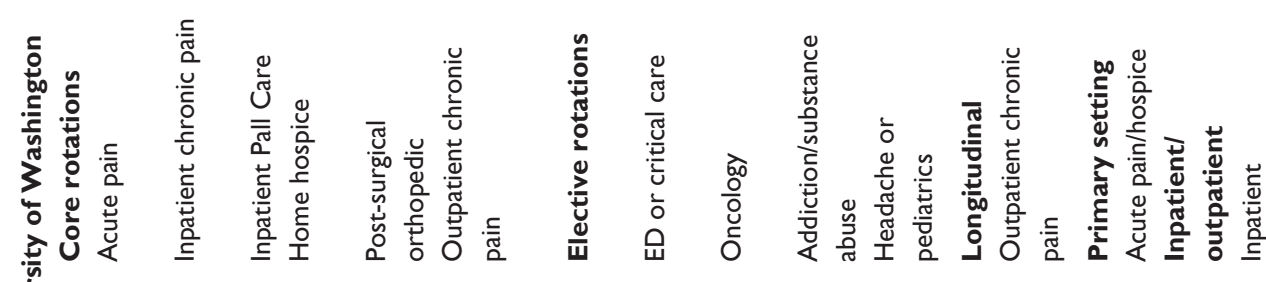

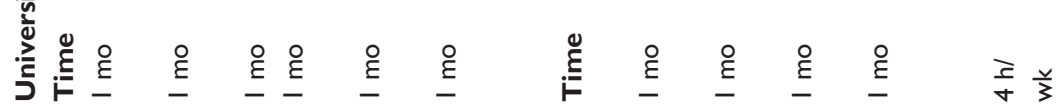

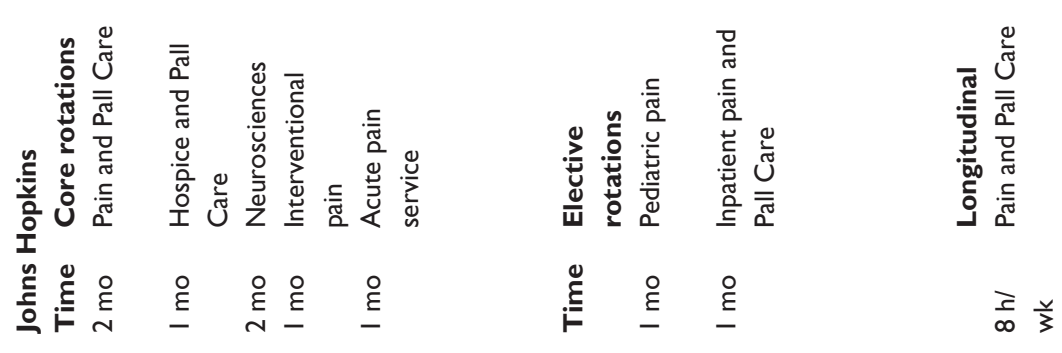

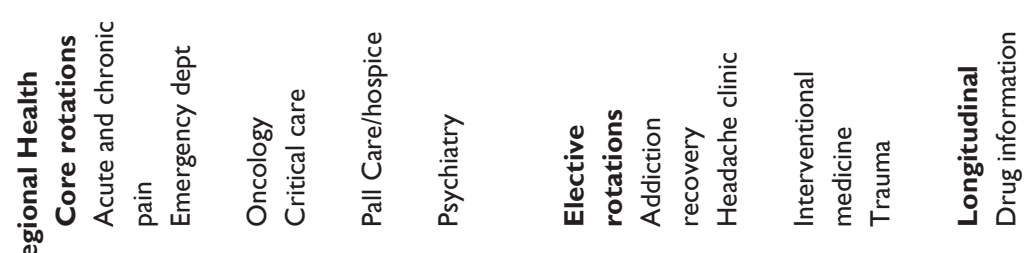

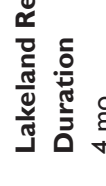


between these core practice areas and ambulatory or chronic pain management. Chronic pain management is focused largely on rehabilitation, assessing compliance, and substance abuse, with useful experiences in rheumatology, neurology, HIV, psychiatry, and addiction medicine. In addition, chronic pain management differs substantially from hospice/palliative care or acute pain management in duration of treatment, which often introduces additional risk factors and complicates management.

Nearly 40 million Americans live with moderate-to-severe pain daily and $40 \%$ of all physician visits are pain related, so the need for chronic pain specialists dominates the clinical stage. ${ }^{31,32}$ Training programs in the area of acute pain and palliative care are integral to clinical practice; however, due to extraordinary demand, it is evident that the current training structure at both the university and postgraduate training levels has not expanded or adapted appropriately to meet society's current and projected challenges in chronic pain management. The demand for specialists in chronic pain probably eclipses that for professionals specialized in palliative care and acute pain combined. These observations raise a few questions: does the current training structure accurately reflect society's current demand for pain specialists? Does it adequately prepare new pharmacy pain specialists for a job market screaming for ambulatory pain specialists? Perhaps the pharmacy profession and public health would be best served with expansion of pain residency experiences that allow greater focus into a specific subspecialty. Ideally, new programs that reflect society's current demand for chronic pain specialists will increase the number of professionals experienced and adept at addressing numerous pain etiologies unique to the ambulatory setting.

\section{The future}

Such a profound paradigm shift as discussed cannot be accomplished with expansion of specialty training programs alone, however, and must be applied to all levels of training beginning at the university level. Of note, only $\sim 3 \%$ of medical schools in the US have portions of their curriculum dedicated to pain education. ${ }^{33}$ In a consensus statement, pharmacy pain specialists recognized a similar deficiency and have recommended a minimum of 5 hours be dedicated to pain therapeutics in pharmacy schools as a minimum standard. ${ }^{11}$ If professional training were to be compared to disease prevalence, it would probably appear similar to Figure 1, in which the disparity between disease prevalence and training programs remains in stark contrast. Despite these glaring training deficiencies, curriculum changes have lagged behind. Many health care professionals do not feel adequately prepared to prescribe and manage opioids, yet misadventures with controlled substances remain among the most common reasons clinicians forfeit professional licensure. ${ }^{34}$ We recommend that PGY-1 and nonpain PGY-2 pharmacy residency programs should consider required rotations in pain management, where possible. This would possibly improve the ability of pharmacists, not traditionally trained in pain management, to assist with pain management concerns in appropriate patients, many of whom can be managed without referrals to specialty care. The current group of PGY-2 Pain and Palliative Care pharmacy residency directors will inherently shape the future of pain pharmacotherapy. They are tasked not only with passing on invaluable clinical experience and practical skills to their residents but also with preparing future pain specialists to meet society's growing demand for specialists in this area. Ideally, previously trained residents should start new residency programs and aid initiatives to expand clinical pharmacy practice in pain management. We recommend emphasis on expansion of PGY-2 pain and palliative care residency programs; however, a greater focus on chronic pain training and experience at both the university and postgraduate training levels is both appropriate and necessary based on society's demand. These initiatives to improve training are paramount to establishing a solid foundation in pain management similar to that emphasized in hypertension, diabetes, and other chronic disease states.

\section{Conclusion}

Health care systems will continue to struggle to meet the demand of patients with chronic pain until significant emphasis is placed on the education and training of health care professionals and additional pain specialists. As issues with inadequately managed pain and unsafe prescribing of pain-related medications move to the forefront of health care and political debate, it is evident that the time has come for clinical pharmacy to expand to meet the growing needs of a society in chronic pain.

\section{Disclosure}

The authors report no conflicts of interest in this work.

\section{References}

1. Institute of Medicine (US) [webpage on the Internet]. Report from the Committee on Advancing Pain Research, Care, and Education. Relieving Pain in America: A Blueprint for Transforming Prevention, Care, Education, and Research. The National Academies Press; 2011. Available from: http://books.nap.edu/openbook.php?record_id=13172\&page=1. Accessed December 13, 2015.

2. Jones C, Mack K, Paulozzi L. Pharmaceutical overdose deaths, United States, 2010. JAMA. 2013;309(7):657-659. 
3. Centers for Disease Control and Prevention (CDC) [webpage on the Internet]. National Vital Statistics System Mortality Data. 2015. Available from: http://www.cdc.gov/nchs/deaths.htm. Accessed December 10, 2015.

4. Stoner S, Ott C, DiPaula B. Psychiatric pharmacy residency training. Am J Pharm Educ. 2010;74(9):163.

5. Ragucci K, O'Bryant C, Campbell K, et al. The need for PGY2-trained clinical pharmacy specialists. Pharmacotherapy. 2014;34(6):e65-e73.

6. Department of Health and Human Services [webpage on the Internet]. The Pharmacist Workforce: A Study of Supply and Demand for Pharmacists. 2000. Available from: http://bhpr.hrsa.gov/healthworkforce/ reports/pharmaciststudy.pdf. Accessed December 10, 2015.

7. ASHP Resident Matching Program [webpage on the Internet]. Match Statistics. Available from: https://natmatch.com/ashprmp/aboutstats. html. Accessed December 10, 2015.

8. American College of Clinical Pharmacy (ACCP). The definition of clinical pharmacy. Pharmacotherapy. 2008;28(6):816-817.

9. Dunn S, Birtcher K, Beavers C, et al. The role of the clinical pharmacist in the care of patients with cardiovascular disease. $\mathrm{J} \mathrm{Am} \mathrm{Coll} \mathrm{Cardiol}$. 2015;66(19):2129-2139.

10. American Society of Health-System Pharmacists (ASHP) [webpage on the Internet]. ASHP Accreditation Standard for Postgraduate Year One (PGY1) Pharmacy Residency Programs. 2012. Available from http://www.ashp.org/DocLibrary/Accreditation/Regulations-Standards/ Guidance-PGY1-Standard-2015.aspx. Accessed December 10, 2015.

11. Herndon C, Strassels S, Strickland J, et al. Consensus recommendations from the strategic planning summit for pain and palliative care pharmacy practice. J Pain Symptom Manage. 2012;43:925-944.

12. Stanos $\mathrm{S}$, Houle T. Multidisciplinary and interdisciplinary management of chronic pain. Phys Med Rehabil Clin NAm. 2006;17(2):e435-e450.

13. Dobscha SK, Corson K, Perrin NA, et al. Collaborative care for chronic pain in primary care: a cluster randomized trial. JAMA. 2009;301(12):1242-1252.

14. Kitahara M, Kojima KK, Ohmura A. Efficacy of interdisciplinary treatment for chronic nonmalignant pain patients in Japan. Clin J Pain. 2006;22(7):647-655.

15. Schappert SM, Burt CW. Ambulatory care visits to physician offices, hospital outpatient departments, and emergency departments: United States, 2001-2002. Vital Health Stat 13. 2006;(159):1-66.

16. Hadi MA, Alldred DP, Briggs M, Munyombwe T, Closs SJ. Effectiveness of pharmacist-led medication review in chronic pain management: systematic review and meta-analysis. Clin J Pain. 2014;30(11):1006-1014

17. McDermott ME, Smith BH, Elliott AM, Bond CM, Hannaford PC, Chambers WA. The use of medication for chronic pain in primary care, and the potential for intervention by a practice-based pharmacist. Fam Pract. 2006;23(1):46-52.

18. Hadi MA, Alldred DP, Briggs M, Marczewski K, Closs SJ. Effectiveness of a community based nurse-pharmacist managed pain clinic: a mixed-methods study. Int J Nurs Stud. 2016;53:219-227.

19. Hanlon JT, Fillenbaum GG, Studenski SA, Ziqubu-Page T, Wall WE Jr. Factors associated with suboptimal analgesic use in community dwelling elderly. Ann Pharmacother. 1996;30(7-8):739-744.

20. Porteous T, Bond C, Hannaford P, Sinclair H. How and why are non-prescription analgesics used in Scotland? Fam Pract. 2005;22(1):78-85.

21. Dole EJ, Murawski MM, Adolphe AB, Aragon FD, Hochstadt B. Provision of pain management by a pharmacist with prescribing authority. Am J Health Syst Pharm. 2007;64(1):85-89.
22. Marra CA, Cibere J, Grubisic M, et al. Pharmacist-initiated intervention trial in osteoarthritis: a multidisciplinary intervention for knee osteoarthritis. Arthritis Care Res. 2012;64(12):1837-1845.

23. CDC [webpage on the Internet]. Common Elements in Guidelines for Prescribing Opioids for Chronic Pain. Available from: http://www. cdc.gov/drugoverdose/prescribing/common-elements.html. Accessed December 10, 2015.

24. Doorenbos AZ, Gordon DB, Tauben D, et al. A blueprint of pain curriculum across prelicensure health sciences programs: one NIH pain consortium center of excellence in pain education (CoEPE) experience. J Pain. 2013;14(12):1533-1538.

25. Upshur CC, Luckmann RS, Savageau JA. Primary care provider concerns about management of chronic pain in community clinic populations. J Gen Intern Med. 2006;21(6):652-655.

26. Darer J, Hwang W, Hoangmai H, Bass E, Anderson G. More training needed in chronic care: a survey of U.S. physicians. Acad Med. 2004;79:541-548.

27. Anderson D, Wang S, Zlateva I. Comprehensive assessment of chronic pain management in primary care: a first phase of a quality improvement initiative at a multisite Community Health Center. Qual Prim Care. 2012;20(6):421-433.

28. Dobscha SK, Corson K, Flores JA, Tansill EC, Gerrity MS. Veterans affairs primary care clinicians' attitudes toward chronic pain and correlates of opioid prescribing rates. Pain Med. 2008;9(5):564-571.

29. American Society of Health-System Pharmacists (ASHP) [webpage on the Internet]. Online Residency Directory. Available from: https:// accred.ashp.org/aps/pages/directory/residencyprogramsearch.aspx. Accessed December 10, 2015.

30. American Society of Health-System Pharmacists (ASHP) [webpage on the Internet]. Overview of PGY2 Pain Management and Palliative Care Pharmacy Residencies. 2009. Available from: http:// www.ashp.org/DocLibrary/Accreditation/Regulations-Standards/ RTP-ObjPalliativePainApril2009.pdf. Accessed December 10, 2015.

31. Arning K, Baron R. Evaluation of symptom heterogeneity in neuropathic pain using assessments of sensory functions. Neurotherapeutics. 2009;6(4):738-748.

32. Nahin RL. Estimates of pain prevalence and severity in adults: United States, 2012. J Pain. 2015;16(8):769-780.

33. Vadivelu N, Mitra S, Hines R, Elia M, Rosenquist RW. Acute pain in undergraduate medical education: an unfinished chapter! Pain Pract. 2012;12(8):663-671.

34. Sawicki N. Character, competence, and the principles of medical discipline. J Health Care Law Policy. 2010;13:285.

35. American Diabetes Association [webpage on the Internet]. Statistics about Diabetes. Available from: http://www.diabetes.org/diabetesbasics/diabetes-statistics/. Accessed December 13, 2015.

36. Centers for Disease Control and Prevention (CDC) [webpage on the Internet]. Data and Statistics - Heart Disease. Available from: http://www. cdc.gov/nchs/fastats/heart-disease.htm. Accessed December 11, 2015.

37. American Cancer Society [webpage on the Internet]. Prevalence of Cancer. Available from: http://www.cancer.org/docroot/CRI/content/ CRI_2_6x_Cancer_Prevalence_How_Many_People_Have_Cancer. asp. Accessed December 13, 2015. 
Integrated Pharmacy Research and Practice

Dovepress

\section{Publish your work in this journal}

Integrated Pharmacy Research and Practice is an international, peer-reviewed, open access, online journal, publishing original research, reports, reviews and commentaries on all areas of academic and professional pharmacy practice. This journal aims to represent the academic output of pharmacists and pharmacy practice with particular focus on integrated care. All papers are carefully

peer reviewed to ensure the highest standards as well as ensuring that we are informing and stimulating pharmaceutical professionals. The manuscript management system is completely online and includes a very quick and fair peer-review system, which is all easy to use. Visit http://www.dovepress.com/ testimonials.php to read real quotes from published authors.

Submit your manuscript here: http://www.dovepress.com/integrated-pharmacy-research-and-practice-journal 